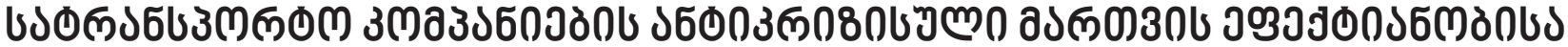

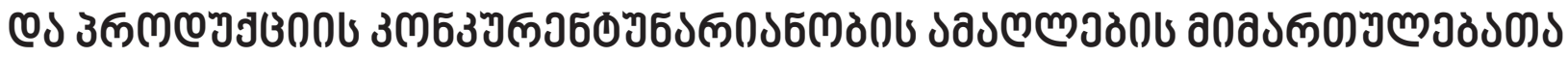

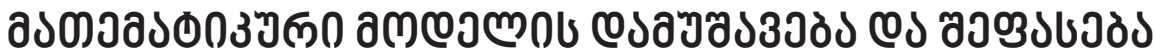

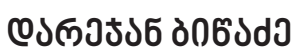

https://doi.org/10.35945/gb.2017.03.024

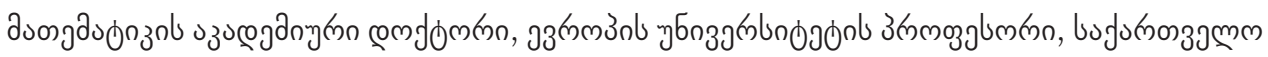

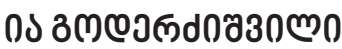

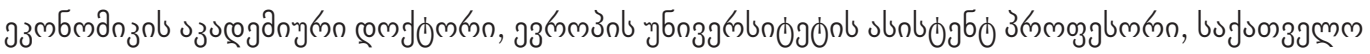

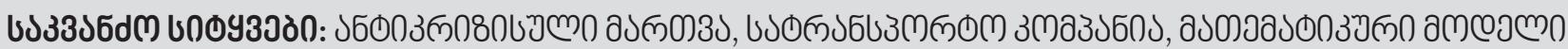

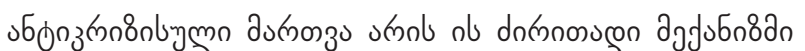

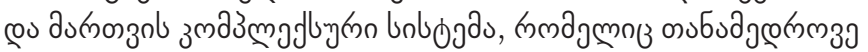

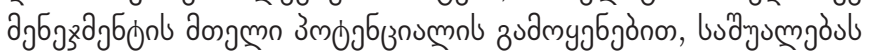

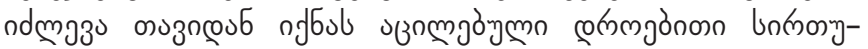

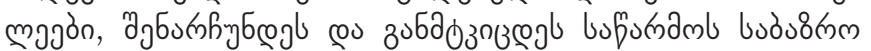

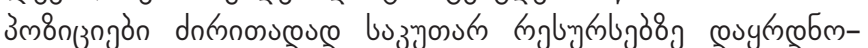

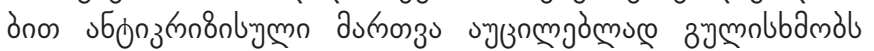

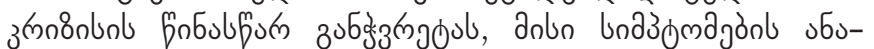

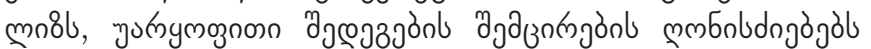

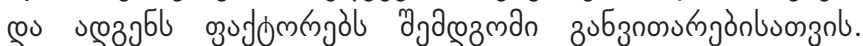

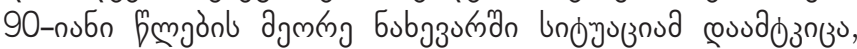

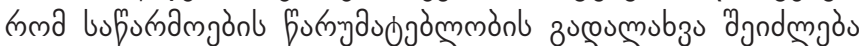

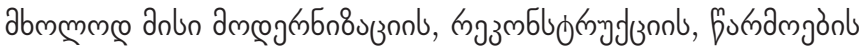

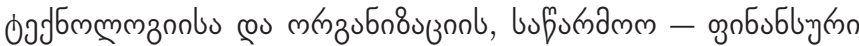

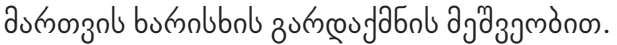

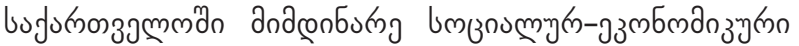

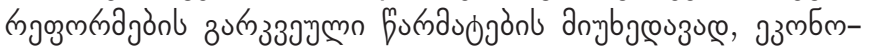

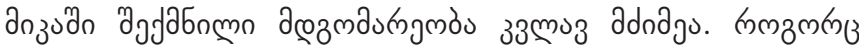

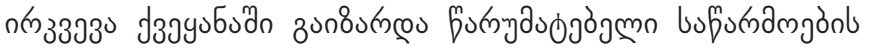

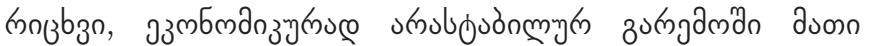

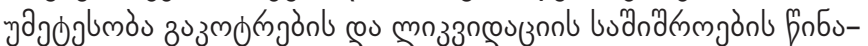

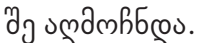

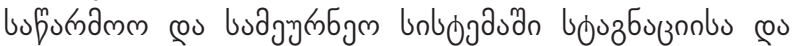

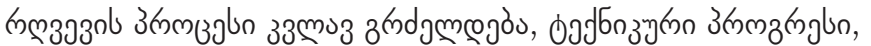

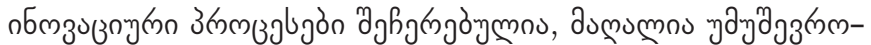

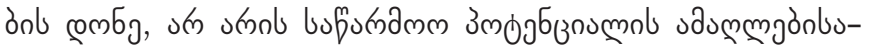

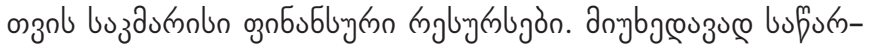

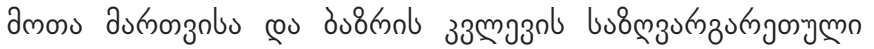

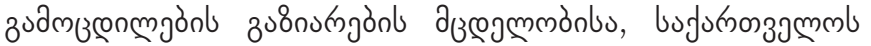

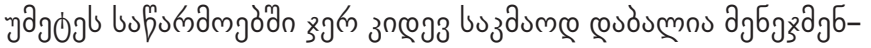

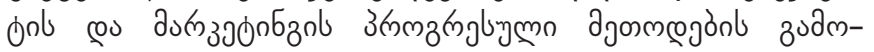

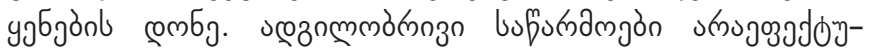

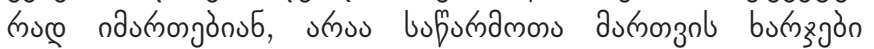

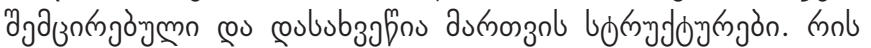

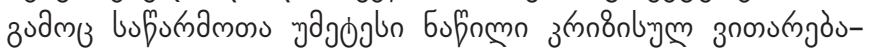

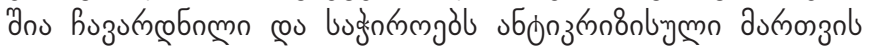

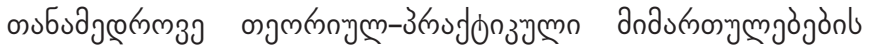

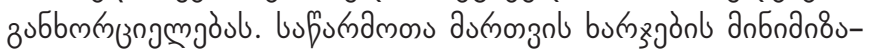

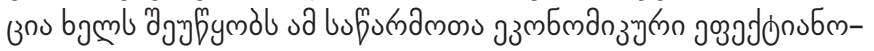

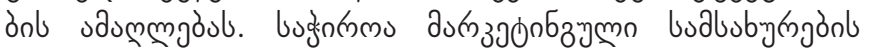

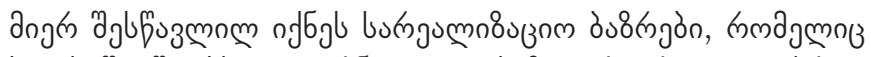

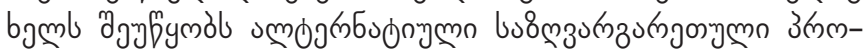

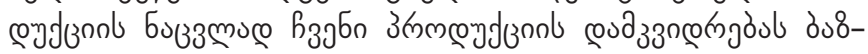

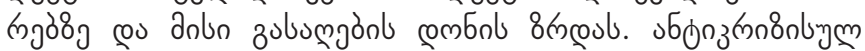

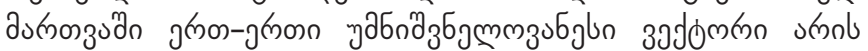

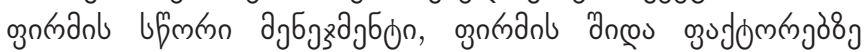

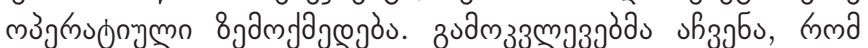

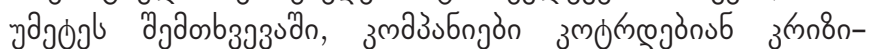

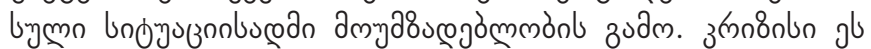

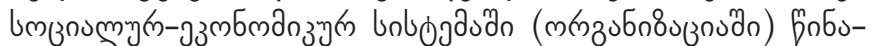

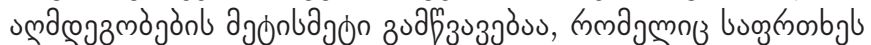

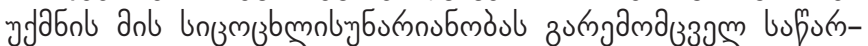

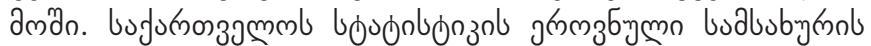

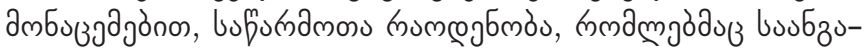

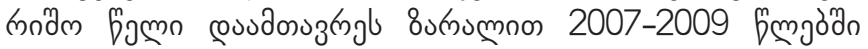

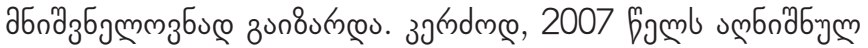

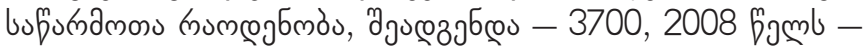

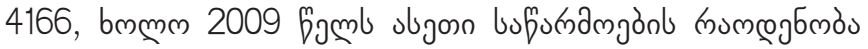

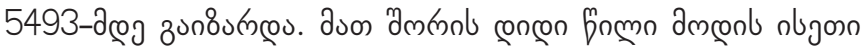

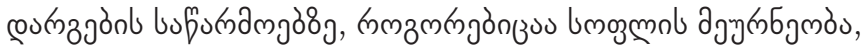

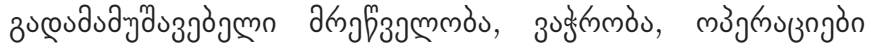

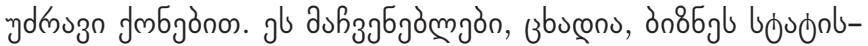

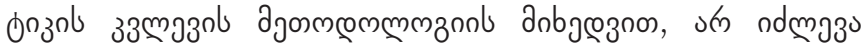

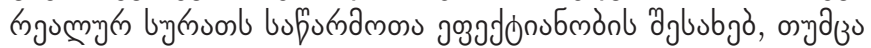

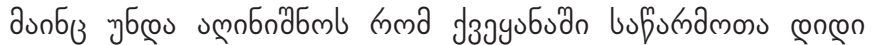

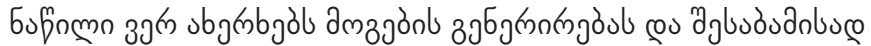

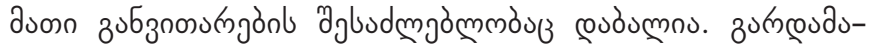

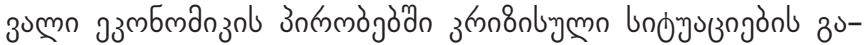

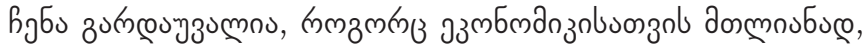

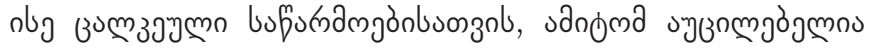

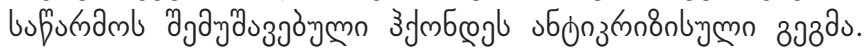
إق

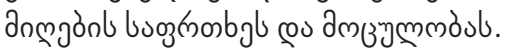

gुn

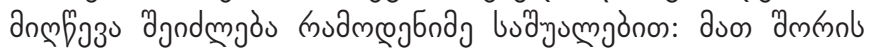

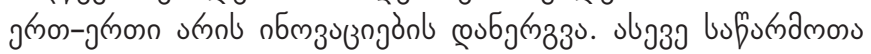

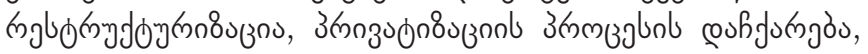

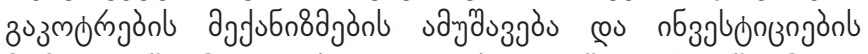

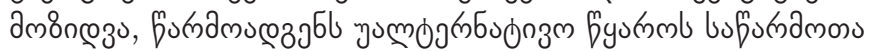

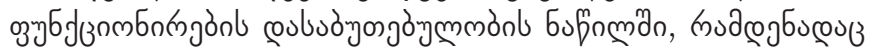




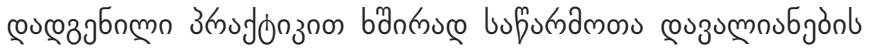

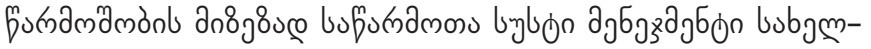
एgò.

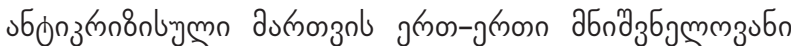

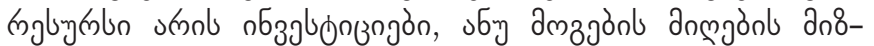

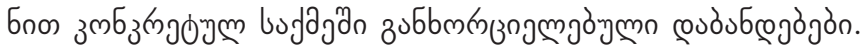

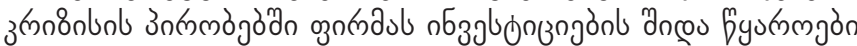

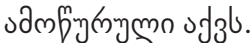

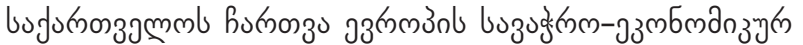

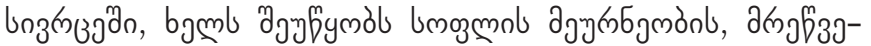

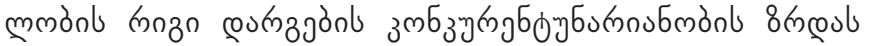

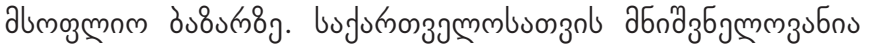

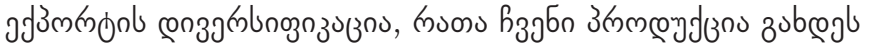

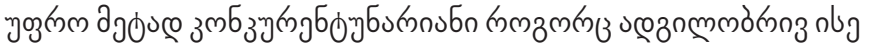

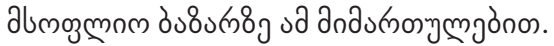

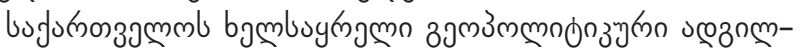

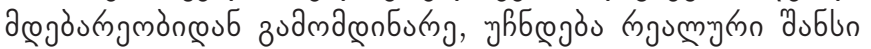

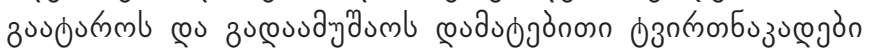

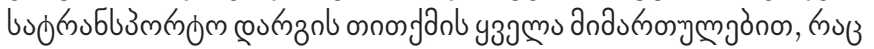

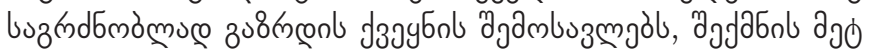

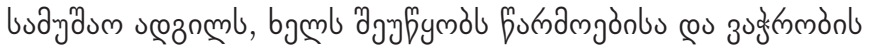

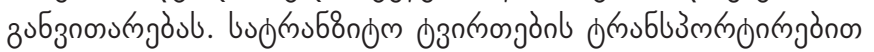

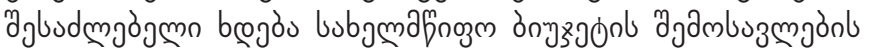

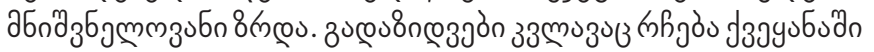

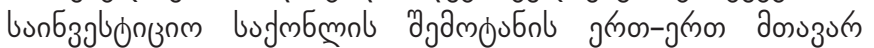

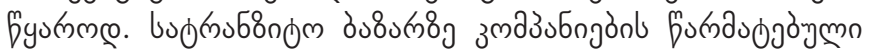

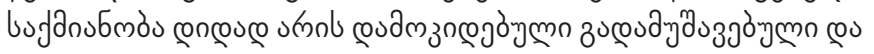

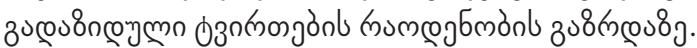

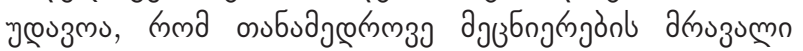

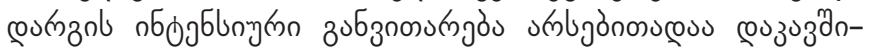

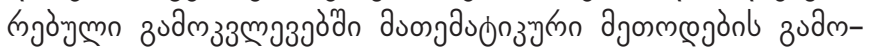

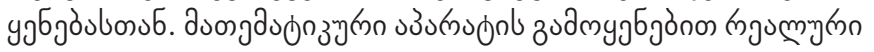
mòngdojôn

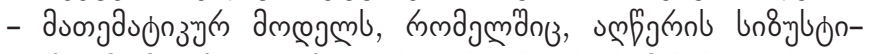

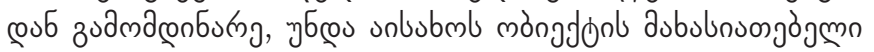

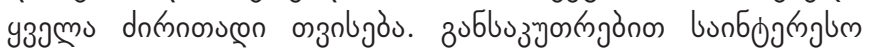

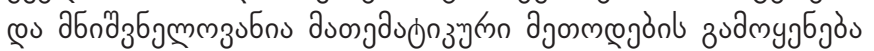

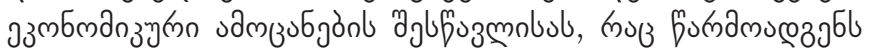

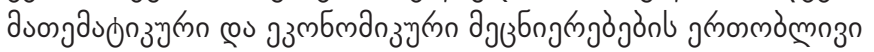

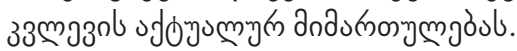

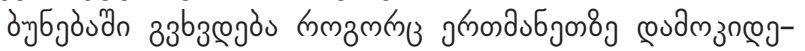

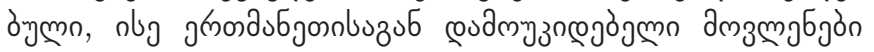

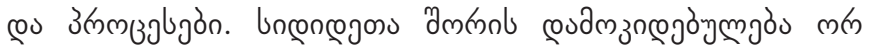

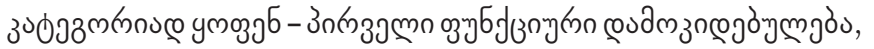

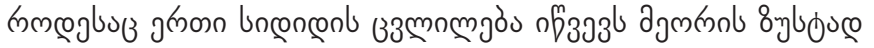

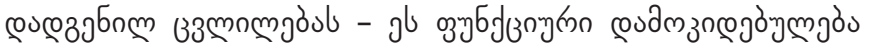

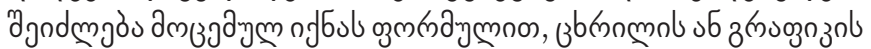

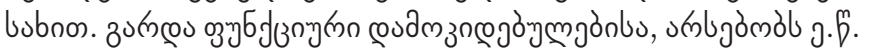

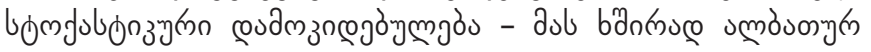

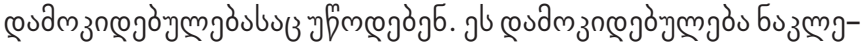

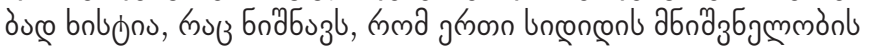

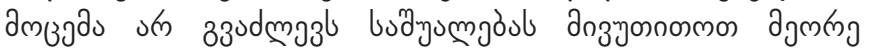

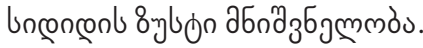

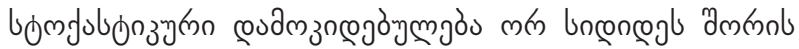

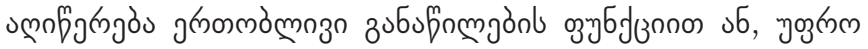

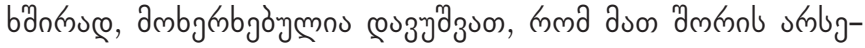

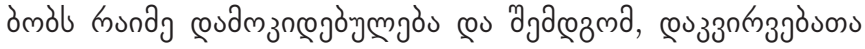

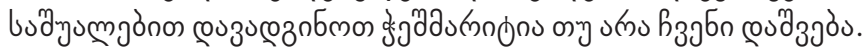

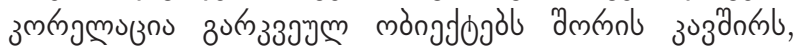

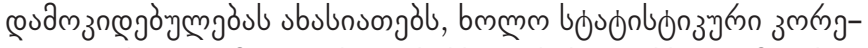

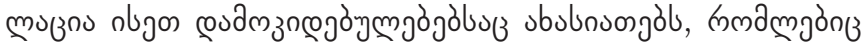

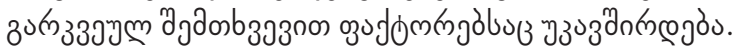

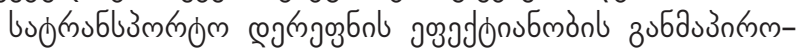

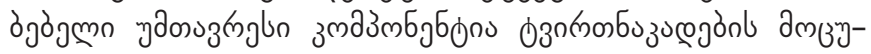

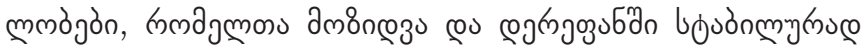

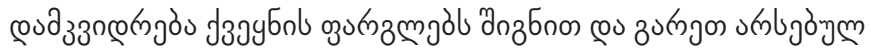

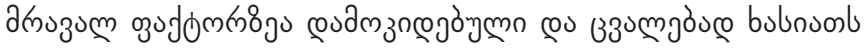

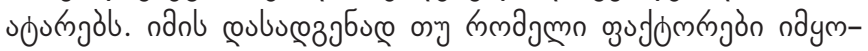

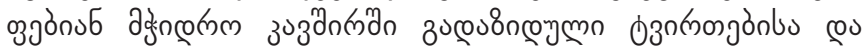

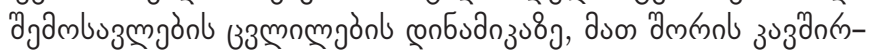

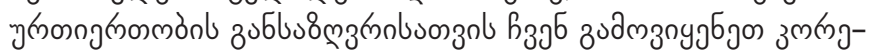

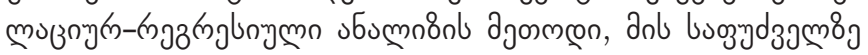

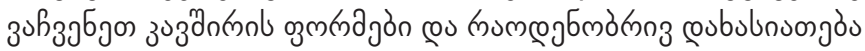

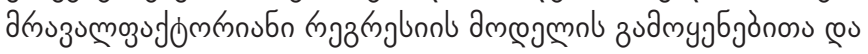

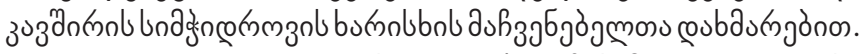

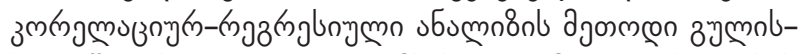

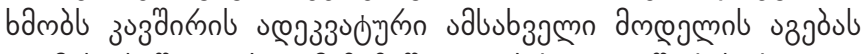
œu dn

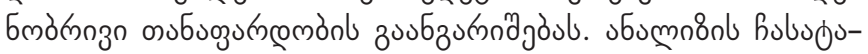

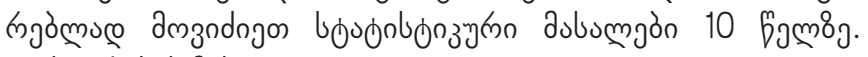

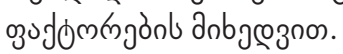

zusб zum

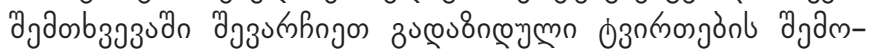

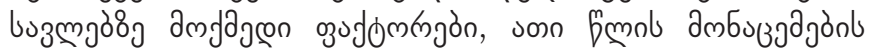
anbjeznon.

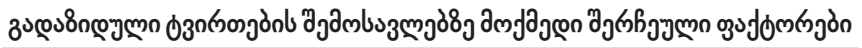

\begin{tabular}{|c|c|}
\hline № & 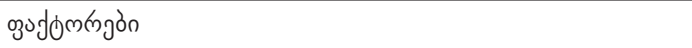 \\
\hline 1 & 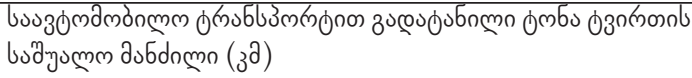 \\
\hline 2 & 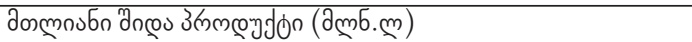 \\
\hline 3 & 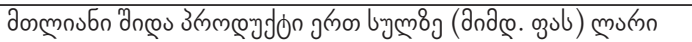 \\
\hline 4 & 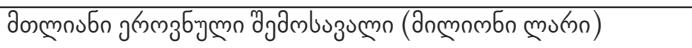 \\
\hline 5 & 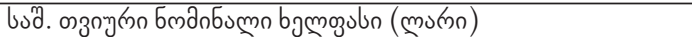 \\
\hline 6 & 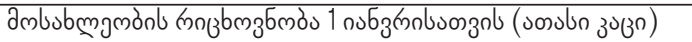 \\
\hline 7 & 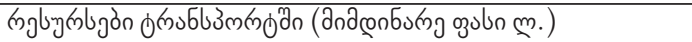 \\
\hline 8 & 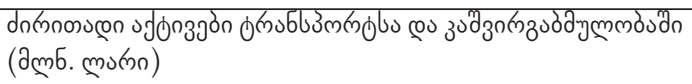 \\
\hline 9 & 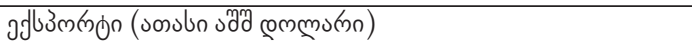 \\
\hline 10 & 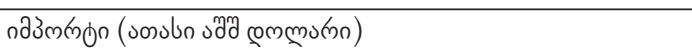 \\
\hline
\end{tabular}

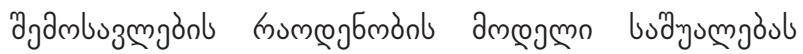

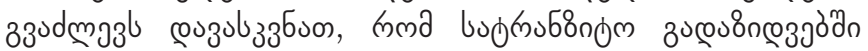

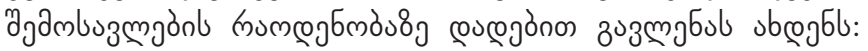

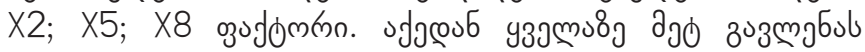

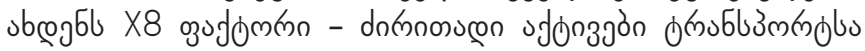




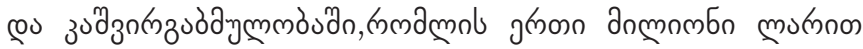

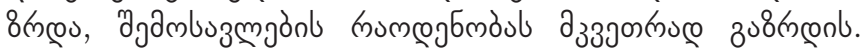

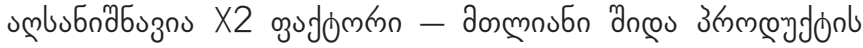

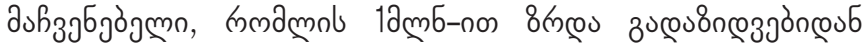

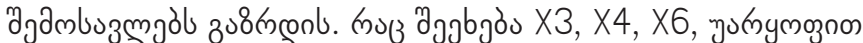

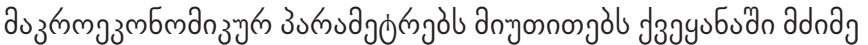

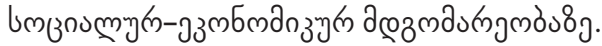

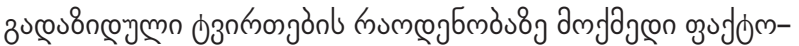

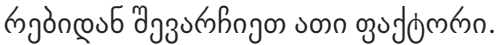

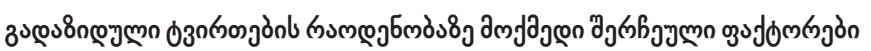

\begin{tabular}{|c|c|}
\hline № & ojudommgòn \\
\hline 1 & 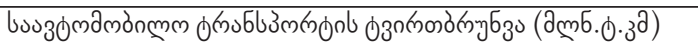 \\
\hline 2 & 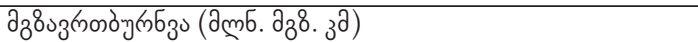 \\
\hline 3 & 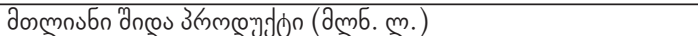 \\
\hline 4 & 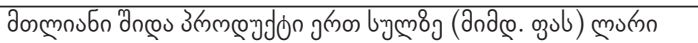 \\
\hline 5 & 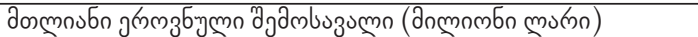 \\
\hline 6 & 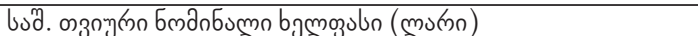 \\
\hline 7 & 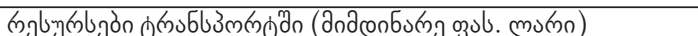 \\
\hline 8 & 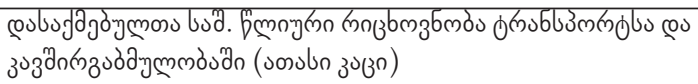 \\
\hline 9 & 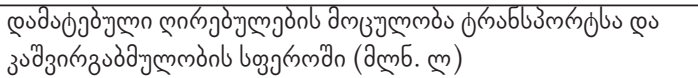 \\
\hline 10 & 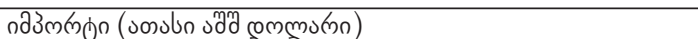 \\
\hline
\end{tabular}

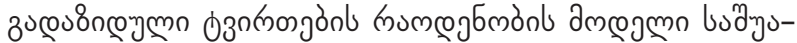

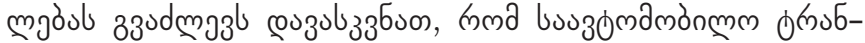

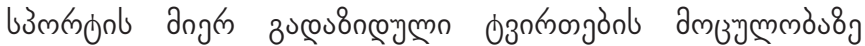

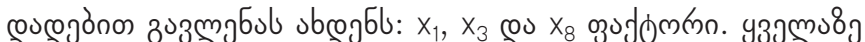

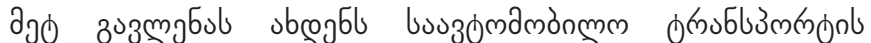

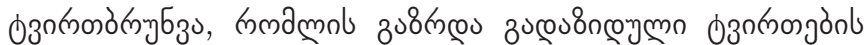

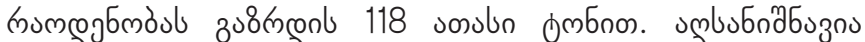

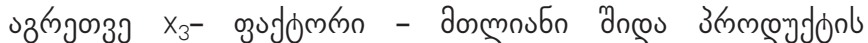

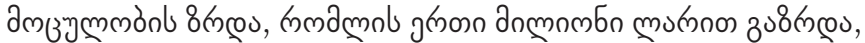

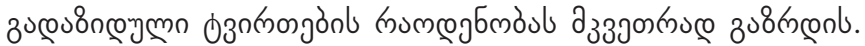

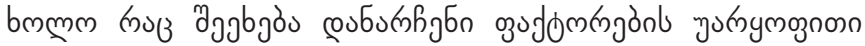

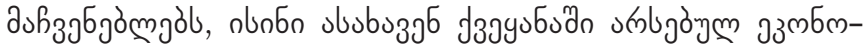

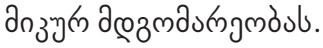

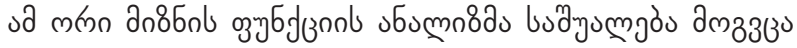

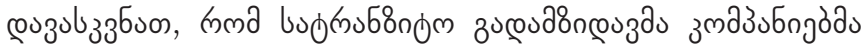

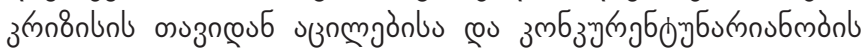

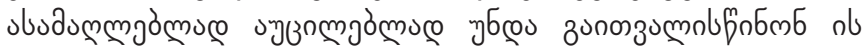

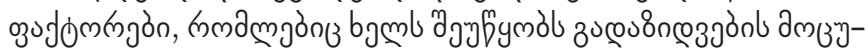

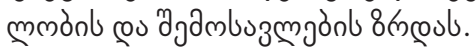

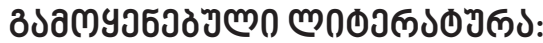

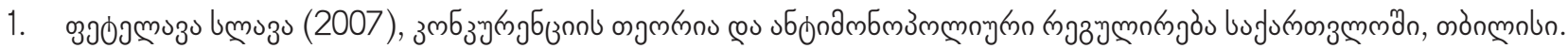

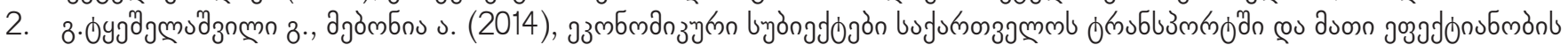

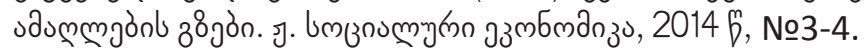

3. Файншмидт Е.,(2012), Антикризисное управление: Учебный курс, Москва.

4. Авдошина 3.А., Антикризисное управление: сущность, диагностика, методики, 2010 Айдинова А. Т., Головко Е. С. Пути повышения конкурентоспособности предприятий // Молодой ученый. - 2015 . - №12.

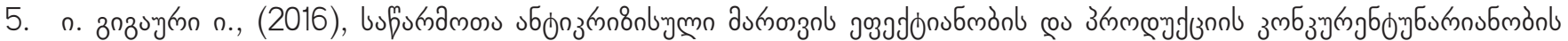

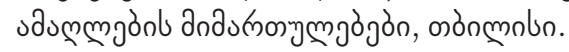

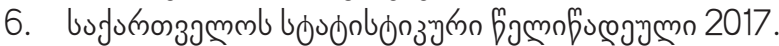

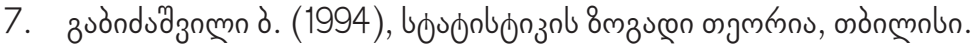




\section{ELABORATION AND ASSESSMENT OF THE MATHEMATICAL MODEL OF ANTI- CRISIS EFFICIENT MANAGEMENT AND PRODUCT COMPETITIVENESS IN LOGISTICS AND PUBLIC TRANSPORT}

DAREJAN BITSADZE

https://doi.org/10.35945/gb.2017.03.024

Doctor of Mathematics, Assistant Professor of European University, Georgia

IA GODERDZISHVILI

Doctor of Economics, Assistant Professor of European University, Georgia

KEYWORDS: ANTI-CRISIS MANAGEMENT, TRANSPORT COMPANY, MATHEMATICAL MODEL

\section{SUMMARY}

Research reviews the ways of improving competitiveness and anti-crisis efficient management of automobile transport for both cargo and passengers, discusses numerous ways of improvements in these fields. Based on analysis of correlative connections of inner and outer factors, publication assesses the competitiveness of transport companies. 